九州大学学術情報リポジトリ

Kyushu University Institutional Repository

\title{
Primary Concentration Measurements of Natural Volatile Organic Compounds in Atmosphere using the Headspace Solid-phase Microextraction Method within the Forest
}

Kim, Geonwoo

Department of Environment and Foret Resources, College of Agriculture \& Life Sciences, Chungnam National University

Park, Bum-Jin

Department of Environment and Foret Resources, College of Agriculture \& Life Sciences, Chungnam National University

Joung, Dawou

Department of Environment and Foret Resources, College of Agriculture \& Life Sciences, Chungnam National University

Yeom, Dong-Geol

Department of Environment and Foret Resources, College of Agriculture \& Life Sciences, Chungnam National University

他

https://doi.org/10.5109/1543411

出版情報: 九州大学大学院農学研究院紀要. 60 (2)，pp.471-476，2015-09-18. Faculty of Agriculture, Kyushu University

バージョン :

権利関係 : 


\title{
Primary Concentration Measurements of Natural Volatile Organic Compounds in Atmosphere using the Headspace Solid-phase Microextraction Method within the Forest
}

\author{
Geonwoo KIM ${ }^{1}$, Bum-Jin PARK ${ }^{1 *}$, Dawou JOUNG ${ }^{1}$, Dong-Geol YEOM ${ }^{1}$ \\ and Shinya KOGA
}

Laboratory of Forest Resources Management, Division of Forest Environmental Sciences, Department of Agro-environmental Sciences, Faculty of Agriculture, Kyushu University, Sasaguri, Fukuoka 811-2415, Japan (Received May 15, 2015 and accepted May 19, 2015)

\begin{abstract}
This study presents methods for the capture and analysis of natural volatile organic compounds (NVOCs) released in the atmosphere of a natural environment. Twenty reference materials were used to draw calibration curves with the headspace solid-phase microextraction (HS-SPME) method. By calculating the calibration curves, obtaining the quantifications of each component, and determining the area ratio of mass numbers by diluting the reference materials of each substance, the coefficients of determination are shown to be a minimum of 0.997 , e.g., $\alpha$-Pinene $\left(R^{2}=0.997\right)$ and $\beta$-Pinene $\left(R^{2}=0.998\right)$, and a high reproducibility is indicated. Detection and quantification limits are below 0.07 and $0.24 \mathrm{ng}$, respectively, for all materials. To determine the amount of NVOCs measured in the atmosphere within forests, sampling was performed for a total of 14 air volume sections collected from a coniferous region using disposable tubes from September to October 2012. The results of the comparative analysis of the detected NVOC substances in these air volumes show the highest efficiency in the $9 \mathrm{~L}$ section. The analyte detection accuracy is between 85.8 and 110.9; this accuracy is high despite the high boiling point, which confirms that the NVOC analysis using the HS-SPME method is effective.
\end{abstract}

Key words: $N V O C$, Terpene, HS-SPME

\section{INTRODUCTION}

Various types of volatile organic compounds (VOCs) that currently exist in the atmosphere have been emitted by both artificial and natural sources. The majority of anthropogenic volatile organic compounds (AVOCs) that are in the urban atmosphere have been emitted by industrial facilities, architecture materials, and vehicles. Some AVOCs in themselves present either harmful toxic or carcinogenic effects and can cause mutations (Aaltonen et al., 2011). Meanwhile, natural volatile organic compounds (NVOCs), which are emitted naturally, have been recognized more recently than artificial emissions, and their emission sources, such as woody material and herbaceous plants, have been known since the 1970s (Akutsu et al., 2006). The terpenoids of NVOCs emitted from forests have been called phytoncides. The phytoncides that have been discovered thus far include volatile and liquid substances, as well as solids; those that come in direct contact with the body while walking in a forest are volatile phytoncides released into the air by plants (BräredChristensson et al., 2012). Phytoncides have different scents according to the type of tree from which they are emitted and the emitted versatile elements (Cheng et al., 2009). In addition, phytoncides are known to have different characteristics depending on their elements (Dayawansa et al., 2003), including insect-proof, anti-

1 Department of Environment and Foret Resources, College of Agriculture \& Life Sciences, Chungnam National University, 99 Daehak-ro, Yuseong-gu, Daejeon 305-764, Republic of Korea

* Corresponding author (E-mail: bjpark@cnu.ac.kr) bacterial, anticancer, antioxidant, antistress, and immunity boosting characteristics (Dimitriades 1981; Elson et al., 1988; Guenther et al., 1991). However, the chemical compositions of phytoncides are not precisely known.

Internationally, various species of trees have been studied through a sampling and analysis method from the United States and Europe (Keith and walker 1995; Kesselmeier and Staudt 1999; Kim et al., 2001; Ji et al., 2002; Hakola et al., 2003). Phytoncides have also been studied in Japan (Li et al., 2006; Kim et al., 2008; Kordali et al., 2008; Lee et al., 2011; Osman, et al., 2011; Ohira and Matsui, 2012; Matsunaga et al., 2013) and Korea, where the study of artificial emissions has been executed for several years (Pio et al., 2001; Pankow et al., 2011). However, many reports do not sufficiently study NVOCs emitted in natural environments, with inadequate understanding of their characteristics, sampling, and analysis methods. In addition, many researchers have used versatile methods because both sampling and analysis methods to study VOCs emitted in nature have not been defined. Accordingly, this study verifies whether the headspace solid-phase microextraction (HS-SPME) method has a sufficiently low data loss and is suitable for NVOC analysis using Pinus densiflora Siebold \& Zucc., which is representative of coniferous species in East Asia.

\section{MATERIALS AND METHODS}

\section{Study site}

The research site for this study is the Daegwallyeong Pinus densiflora forest area located in SeongsanMyeon, Gangneung City, Gangwon-do in South Korea. 
There are several types of Pinus densiflora Siebold \& Zucc. trees in this location, with the Pinus densiflora Siebold \& Zucc. forma erecta Uyeki, which has straight red stems, as the primary tree in this study. The reservation condition of the target site is favorable, and the research was performed in a forest area approximately $20 \mathrm{~m}$ off of a trail, such that the trail did not contaminate the atmosphere environment. The research site is a mountainside located at an altitude of $240 \mathrm{~m}$ and is a dominant area of five age classes of fine trees. The area is rugged with a steep slope and is of river-bed type. Its sedimentation is creep, the aspect is southwest, and wind exposure is normal as for a forest land.

\section{Measurement factors}

Natural volatile organic compounds

VOCs are either liquid or gas organic compounds that have boiling points under $100^{\circ} \mathrm{C}$ and are easily evaporated into the atmosphere. This study concentrates on methods of analyzing NVOCs. The majority of NVOCs emitted in forests is generated by trees. Terpene compounds, which are types of NVOCs emitted by trees, are built from multiple base units of isoprene, which contains five carbon and eight hydrogen atoms. Terpene compounds usually have a strong smell, minimal water solubility, and are located in plants, as well as in animals and microorganisms. A common, large NVOC group terpenes are classified by the number of isoprene units in the molecules, e.g., hemiterpenes (one isoprene unit), monoterpenes (two isoprene units), and sesquiterpenes (three isoprene units). Emission inventories show that isoprene units and monoterpenes are the most prominent compounds. This study selected a total of 20 species of isoprenes and monoterpenes (99\%, Aldrich, USA), including isoprene, $\alpha$-Pinene, $\beta$-Pinene, and camphene, for analysis.

\section{Selection of measurement materials}

As part of an effort in Forest Science \& Technology projects, the Korea Forest Service recently performed a material contents survey pertaining to the health effects of NVOCs, selecting 20 species elements emitted from various coniferous species. Types of VOCs emitted from plants are estimated to be over 25,000, and chemical species of NVOCs emitted into the atmosphere by plants are 147, over half of which are terpenes, according to the Model of Emissions of Gases and Aerosols from Nature 2.1 released by the National Center for Atmospheric Research (NCAR) in 2012, which shows 53 species' materials out of the total 147 . Medical studies researching the effects of NVOCs and how to cope with the diseases they cause have been published internationally (Yatagai et al., 1995; Trapp et al., 2001; Tani et al., 2002; Wang et al., 2006; Tani and Kawawata, 2008; Yang et al., 2011; Wang et al., 2012).

Therefore, unlike previous efforts to analyze NVOCs, we have surveyed the existing literature to determine how materials have been observed to affect the body thus far. The primary keywords for the literature search were BRM (biological response modifier), phytochemicals, nutraceuticals (nutrition and pharmaceuticals), aromas, and essential oils. Accordingly, keywords resulting in high frequency outputs from previous studies were used in this study to guide the selection of materials to represent VOC types present in the atmosphere.

\section{Measurement methods NVOCs}

The adsorption tube method was used in this study to collect samples. A disposable tube (ORBO 402, Supelco, USA) filled with Tenax TA was used as the adsorption tube. The sample capture device was a mini pump (MP- $-30 \mathrm{KN}$, SIBATA, Japan), and the calibration was proceeded by adsorption error to use a flow meter before use. The total adsorption flow was sampled at $100 \mathrm{~mL} /$ min for air volumes of $1,3,6,9,12,24$, and $48 \mathrm{~L}$. The sampling equipment was installed in accordance with the horizontal height of the tripod, $1.5 \mathrm{~m}$ from the ground, and calculated the average value from duplicate sampling at every location. Disposable polyethylene gloves and antibacterial masks were used to prevent artificial error when in contact with the tube during installation. After sampling, sample tubes were maintained at temperatures below $4^{\circ} \mathrm{C}$ and analyzed within $48 \mathrm{~h}$.

\section{HS-SPME Method}

The extraction method for the samples of VOCs and synthetic organic compounds (SOCs) was expensive and time consuming, and contamination materials that are harmful to the body and environment were emitted from the use of organic solvents. In addition, there was a loss in sampling the pretreatments, which caused an error, as well as low reproducibility, because of contamination during extraction or enrichment. To mitigate this issue, solid-phase micro extraction (SPME) is a simple method to extract pretreatments without using organic solvents.

Accordingly, the sampling for this study used pretreatments from the HS-SPME method and applied the NVOC analysis in an effort to analyze the sample using GC-MS. In this setup, $1 \mathrm{~mL} \mathrm{MeOH}$ flowed into the sample, which was then moved to a $10 \mathrm{~mL}$ of headspace vial containing $4 \mathrm{~mL}$ of purified water. Phenanthrrene-10 $(1 \mathrm{mg} / \mathrm{L} \times 50 \mu \mathrm{L})$ was then applied through internal standards, and the sample was injected into the GC hole

Table 1. HS-SPME operating parameters for NVOCs

\begin{tabular}{ll}
\hline \multicolumn{1}{c}{ Parameter } & Value \\
\hline Pre-Incubation Time & $20 \mathrm{~s}$ \\
Incubation Temp. & $40^{\circ} \mathrm{C}$ \\
Fiber Condition Temp. & $280^{\circ} \mathrm{C}$ \\
Agitator Speed & $500 \mathrm{rpm}$ \\
Vial Penetration & $22 \mathrm{~mm}$ \\
Extraction Time & $30 \mathrm{~m}$ \\
Injection Penetration & $54 \mathrm{~mm}$ \\
Desorption Time & $5 \mathrm{~m}$ \\
Post-Fiber Condition Time & $10 \mathrm{~m}$ \\
\hline
\end{tabular}


and analyzed by GC-MS after boiling for $15 \mathrm{~min}$ at $40^{\circ} \mathrm{C}$. Polydimethylsiloxane/divinylbenzene (PDMS/DVB) was used for the fiber, and a chromatogram was recorded for either a single or quantitative ion analysis. The peak position of the retention time was measured for each material, and each quantity was acquired from the calibration curve, allowing the calculation of the sampling concentration (Table 1).

\section{RESULTS}

\section{Calibration curve}

There are few tests to confirm both the analysis device and the procedures. First, this study used 20 species of standard materials, such as $\alpha$-Pinene and $\beta$-Pinene, to draw the calibration curve. Using the calibration curve to calculate each element's mass number and the square of its rate of diluting standard materials, a majority of the materials has a linearity greater than 0.997, e.g., $\alpha$-Pinene $\left(R^{2}=0.997\right), \beta$-Pinene $\left(R^{2}=\right.$ $0.998)$, and D-Limonene $\left(R^{2}=0.999\right)$. The experiments using these materials also have a high reproducibility with respect to the liner correlation coefficient, which is suitable for analysis.

\section{Limits of detection and quantification}

The limit of detection (LOD) is the minimum concentration of a substance required for its detection, and the limit of quantification (LOQ) is the limit at which different quantities of a substance can be distinguished from each other. An extraction following the test procedure described above using 7ea sample with added analysis materials was performed to set the estimated LOD for the material tube used to analyze the LOD. This extraction calculated a standard deviation for each sample; the LOD was set as the standard deviation multiplied by 3.14, and the LOQ was the standard deviation multiplied by 10 .

To verify whether the above values can detect substantial materials, we applied the LOQ to the LOD analysis material tube and then performed the extraction as described above. Requirements for detection were set at 3 times the signal-to-noise ratio. As a result, the LOD was below $0.07 \mathrm{ng}$ over all materials, and the LOQ was below $0.24 \mathrm{ng}$ (Table 2).

\section{Accuracy and precision}

The standard material concentration was set at 10 times the LOQ concentration of purified water, and the standard deviation and average value were calculated as above. After performing five measurements, the coefficient of variance measured within $4.2 \%-12.3 \%$, and the precision was within 10\%, except with terpineolene, cedrol, $\gamma$-Terpinene, cineole, and isoprene. As a result, the accuracy was within $100 \%$ for such materials as caryophyllene and $\delta$-3-carene, among others. Of the 20 species of materials, the accuracy of 15 species was under $100 \%$ and that of the other 5 species was over 100\% (Table 3).

\section{Sampling determination}

In this study, the conditions of the physical environment, such as temperature, wind speed, humidity, illuminance, and other conditions, which are a flow speed, and the species and ages of trees, were set to determine the sampling of phytoncides. The results of sampling NVOC detection show that the most efficient detection was in

Table 2. Analytical results of LOD-LOQ measurements

\begin{tabular}{|c|c|c|c|c|c|c|c|c|c|c|}
\hline Compound & $\begin{array}{l}\text { Spike } \\
\text { Conc. }\end{array}$ & Conc.1 & Conc. 2 & Conc. 3 & Conc. 4 & Conc. 5 & Conc.6 & Conc. 7 & LOD & $\mathrm{LOQ}$ \\
\hline Isoprene & 0.5 & 0.478 & 0.687 & 0.385 & 0.545 & 0.780 & 0.601 & 0.472 & 0.428 & 1.36 \\
\hline$\alpha$-Pinene & 0.05 & 0.046 & 0.048 & 0.053 & 0.064 & 0.040 & 0.067 & 0.048 & 0.031 & 0.10 \\
\hline Camphene & 0.05 & 0.034 & 0.049 & 0.057 & 0.051 & 0.048 & 0.063 & 0.053 & 0.028 & 0.09 \\
\hline$\beta$-Pinene & 0.05 & 0.037 & 0.036 & 0.041 & 0.051 & 0.032 & 0.054 & 0.039 & 0.026 & 0.08 \\
\hline$\delta-3$-Carene & 0.05 & 0.039 & 0.047 & 0.047 & 0.051 & 0.043 & 0.059 & 0.046 & 0.020 & 0.06 \\
\hline Myrcene & 0.05 & 0.039 & 0.035 & 0.038 & 0.048 & 0.049 & 0.052 & 0.047 & 0.021 & 0.07 \\
\hline$\alpha$-Phellandrene & 0.05 & 0.058 & 0.050 & 0.047 & 0.050 & 0.067 & 0.050 & 0.055 & 0.022 & 0.07 \\
\hline$\alpha$-Terpinene & 0.05 & 0.046 & 0.072 & 0.044 & 0.055 & 0.055 & 0.058 & 0.041 & 0.033 & 0.11 \\
\hline D-Limonene & 0.05 & 0.051 & 0.052 & 0.059 & 0.064 & 0.039 & 0.061 & 0.040 & 0.031 & 0.10 \\
\hline Cineole & 0.05 & 0.036 & 0.032 & 0.036 & 0.070 & 0.043 & 0.097 & 0.051 & 0.073 & 0.23 \\
\hline$\gamma$-Terpinene & 0.05 & 0.052 & 0.053 & 0.038 & 0.052 & 0.046 & 0.049 & 0.031 & 0.026 & 0.08 \\
\hline Cymene & 0.05 & 0.046 & 0.054 & 0.053 & 0.060 & 0.042 & 0.063 & 0.049 & 0.023 & 0.07 \\
\hline Terpinolene & 0.05 & 0.064 & 0.059 & 0.051 & 0.058 & 0.055 & 0.042 & 0.034 & 0.033 & 0.11 \\
\hline Linalool & 0.05 & 0.063 & 0.067 & 0.062 & 0.053 & 0.050 & 0.064 & 0.065 & 0.021 & 0.07 \\
\hline Camphor & 0.1 & 0.090 & 0.081 & 0.070 & 0.106 & 0.081 & 0.125 & 0.072 & 0.063 & 0.20 \\
\hline$\alpha$-Humulene & 0.05 & 0.054 & 0.050 & 0.046 & 0.045 & 0.054 & 0.050 & 0.044 & 0.013 & 0.04 \\
\hline Terpineol & 0.05 & 0.084 & 0.042 & 0.039 & 0.058 & 0.035 & 0.091 & 0.037 & 0.074 & 0.24 \\
\hline Cedrol & 0.05 & 0.037 & 0.041 & 0.071 & 0.041 & 0.019 & 0.082 & 0.076 & 0.075 & 0.24 \\
\hline
\end{tabular}


Table 3. Precision and accuracy of NVOCs

\begin{tabular}{|c|c|c|c|c|}
\hline Compound & Spike Conc. (ng) & Average $\pm \mathrm{SD}$ (ng) & Accuracy (\%) & Precision (\%) \\
\hline \multirow{2}{*}{ Isoprene } & 1.0 & $0.96 \pm 0.12$ & 95.7 & 12.3 \\
\hline & 5.0 & $4.91 \pm 0.56$ & 98.2 & 11.3 \\
\hline \multirow{2}{*}{$\alpha$-Pinene } & 0.5 & $0.47 \pm 0.03$ & 94.5 & 7.2 \\
\hline & 2.5 & $2.46 \pm 0.18$ & 98.4 & 7.4 \\
\hline \multirow{2}{*}{ Camphene } & 0.5 & $0.45 \pm 0.03$ & 90.8 & 7.3 \\
\hline & 2.5 & $2.46 \pm 0.30$ & 98.6 & 12.1 \\
\hline \multirow{2}{*}{$\beta$-Pinene } & 0.5 & $0.47 \pm 0.04$ & 93.7 & 8.0 \\
\hline & 2.5 & $2.43 \pm 0.22$ & 97.0 & 9.2 \\
\hline \multirow{2}{*}{$\delta-3-$ Carene } & 0.5 & $0.43 \pm 0.04$ & 86.8 & 9.4 \\
\hline & 2.5 & $2.60 \pm 0.20$ & 103.9 & 7.6 \\
\hline \multirow{2}{*}{ Myrcene } & 0.5 & $0.48 \pm 0.04$ & 96.3 & 7.5 \\
\hline & 2.5 & $2.29 \pm 0.13$ & 91.6 & 5.7 \\
\hline \multirow{2}{*}{$\alpha$-Phellandrene } & 0.5 & $0.44 \pm 0.04$ & 87.5 & 8.6 \\
\hline & 2.5 & $2.41 \pm 0.18$ & 96.4 & 7.7 \\
\hline \multirow{2}{*}{$\alpha$-Terpinene } & 0.5 & $0.44 \pm 0.04$ & 88.8 & 8.8 \\
\hline & 2.5 & $2.43 \pm 0.26$ & 97.0 & 10.7 \\
\hline \multirow{2}{*}{ D-Limonene } & 0.5 & $0.46 \pm 0.04$ & 92.2 & 9.3 \\
\hline & 2.5 & $2.44 \pm 0.23$ & 97.5 & 9.6 \\
\hline \multirow{2}{*}{ Cineole } & 0.5 & $0.49 \pm 0.06$ & 97.2 & 12.2 \\
\hline & 2.5 & $2.62 \pm 0.25$ & 104.7 & 9.6 \\
\hline \multirow{2}{*}{$\gamma$-Terpinene } & 0.5 & $0.46 \pm 0.05$ & 92.0 & 11.8 \\
\hline & 2.5 & $2.34 \pm 0.13$ & 93.4 & 5.7 \\
\hline \multirow{2}{*}{ Cymene } & 0.5 & $0.48 \pm 0.05$ & 96.1 & 10.0 \\
\hline & 2.5 & $2.52 \pm 0.28$ & 100.7 & 11.2 \\
\hline \multirow{2}{*}{ Terpinolene } & 0.5 & $0.43 \pm 0.03$ & 86.7 & 7.4 \\
\hline & 2.5 & $2.54 \pm 0.11$ & 101.4 & 4.4 \\
\hline \multirow{2}{*}{ Linalool } & 0.5 & $0.50 \pm 0.05$ & 100.7 & 9.4 \\
\hline & 2.5 & $2.73 \pm 0.21$ & 109.3 & 7.7 \\
\hline \multirow{2}{*}{ Camphor } & 0.5 & $0.52 \pm 0.03$ & 104.5 & 5.2 \\
\hline & 2.5 & $2.39 \pm 0.20$ & 95.4 & 8.2 \\
\hline \multirow{2}{*}{$\alpha$-Humulene } & 0.5 & $0.44 \pm 0.03$ & 88.8 & 7.6 \\
\hline & 2.5 & $2.34 \pm 0.18$ & 93.8 & 7.6 \\
\hline \multirow{2}{*}{ Terpineol } & 0.5 & $0.55 \pm 0.06$ & 110.9 & 10.4 \\
\hline & 2.5 & $2.62 \pm 0.18$ & 104.9 & 6.7 \\
\hline \multirow{2}{*}{ Cedrol } & 0.5 & $0.51 \pm 0.06$ & 102.2 & 11.5 \\
\hline & 2.5 & $2.76 \pm 0.24$ & 110.3 & 8.6 \\
\hline
\end{tabular}

the case of $9 \mathrm{~L}$ sampling to detect 13 species (Table 4).

\section{DISCUSSION}

This study suggests alternatives for the sampling and analysis of NVOCs emitted from natural forest environments. Several pretreatment steps were inevitable for the analysis of the existing VOC materials. However, the HS-SPME method is a simple pretreatment method that does not use organic solvents and allowed the extraction of NVOCs by GC/MS analysis. This saved analysis time and minimized the contamination of the analysis materi- als.

This study used 20 species of standard materials, such as $\alpha$-Pinene and $\beta$-Pinene, to draw the calibration curve by HS-SPME. Using the calibration curve to calculate each element's mass number and the square of its rate of diluting standard materials, the majority of the materials was shown to have a good linearity of over 0.997. The experiments also have a high reproducibility with respect to the liner correlation coefficient, which is suitable for analysis.

The LOD was below $0.07 \mathrm{ng}$ for all the materials, and the LOQ was below $0.24 \mathrm{ng}$. The study of the relationship 
Table 4. Analytical results of air volume tests

(unit: ng)

\begin{tabular}{lccccccc}
\hline \multicolumn{1}{c}{ Compound } & $1 \mathrm{~L}$ & $3 \mathrm{~L}$ & $6 \mathrm{~L}$ & $9 \mathrm{~L}$ & $12 \mathrm{~L}$ & $24 \mathrm{~L}$ & $48 \mathrm{~L}$ \\
\hline Isoprene & $\mathrm{ND}$ & $\mathrm{ND}$ & $\mathrm{ND}$ & $\mathrm{ND}$ & $\mathrm{ND}$ & $\mathrm{ND}$ & $\mathrm{ND}$ \\
$\alpha$-Pinene & 0.18 & 0.56 & 0.65 & 0.73 & 1.26 & 1.95 & 3.08 \\
Camphene & $\mathrm{ND}$ & 0.15 & 0.18 & 0.21 & 0.48 & 0.91 & 1.68 \\
$\beta$-Pinene & 0.21 & 0.62 & 0.87 & 1.12 & 1.71 & 2.80 & 4.92 \\
$\delta$-3-Carene & 0.14 & 0.11 & 0.09 & 0.12 & 0.05 & 0.07 & 0.18 \\
Myrcene & 0.14 & 0.23 & 0.13 & 0.16 & 0.08 & 0.10 & 0.23 \\
Phellandrene & 0.12 & 0.25 & 0.15 & 0.07 & 0.02 & 0.14 & 0.33 \\
$\alpha-$ Terpinene & 0.02 & 0.30 & 0.13 & 0.09 & 0.06 & 0.12 & 0.43 \\
D-Limonene & 1.34 & 1.23 & 0.73 & 1.14 & 1.39 & 1.56 & 3.70 \\
Cineole & $\mathrm{ND}$ & $\mathrm{ND}$ & $\mathrm{ND}$ & $\mathrm{ND}$ & $\mathrm{ND}$ & $\mathrm{ND}$ & $\mathrm{ND}$ \\
$\gamma$-Terpinene & 0.57 & 0.67 & 0.64 & 0.37 & 0.59 & 0.64 & 1.09 \\
Cymene & 0.22 & 0.37 & 0.25 & 0.18 & 0.18 & 0.28 & 0.56 \\
Terpinolene & 0.18 & 0.51 & 0.36 & 0.16 & 0.27 & 0.42 & 0.93 \\
Linalool & $\mathrm{ND}$ & $\mathrm{ND}$ & $\mathrm{ND}$ & $\mathrm{ND}$ & $\mathrm{ND}$ & $\mathrm{ND}$ & $\mathrm{ND}$ \\
Camphor & $\mathrm{ND}$ & $\mathrm{ND}$ & $\mathrm{ND}$ & 0.14 & 0.47 & 0.77 & 1.25 \\
Caryophyllene & $\mathrm{ND}$ & $\mathrm{ND}$ & $\mathrm{ND}$ & $\mathrm{ND}$ & $\mathrm{ND}$ & $\mathrm{ND}$ & $\mathrm{ND}$ \\
$\alpha$-Humulene & $\mathrm{ND}$ & $\mathrm{ND}$ & $\mathrm{ND}$ & $\mathrm{ND}$ & $\mathrm{ND}$ & $\mathrm{ND}$ & $\mathrm{ND}$ \\
Terpineol & 0.88 & 0.86 & 0.79 & 1.10 & 1.10 & 1.78 & 1.21 \\
\hline
\end{tabular}

between VOC emission and secondary organic aerosols was also performed more widely. This means that it accounts not only for what is inside the forest but also the overall emission quantities to calculate the NVOC emission coefficient in the entire forest. To make up for this matter in NCAR, accurate NVOC concentrations were calculated using enclosure chambers on trees, but NVOC measurements in a natural environment without artificial conditions are incomplete. There is some advanced research in Korea to take measurements in forests; however, the sampling flow quantity is different, which introduces uncertainty in determining standard sampling quantities.

Therefore, to determine the sampling quantity of NVOCs in the forest atmosphere, this study used both a mini pump and a disposal tube filled with Tanax TA from a Pinus densiflora forest that is known to emit a large quantity of NVOCs from a needle-leaf tree. The total 14 ea sampling was divided to measure air volumes of 1 , $3,6,9,12,24$, and $48 \mathrm{~L}$. We also measured duplicate sampling in each location so as to minimize the standard deviation and used the average value during analysis.

As a result of the comparison analysis over the extracted NVOC materials, the efficiency of the $9 \mathrm{~L}$ case had the highest result. The accuracy of the material detection was in the range of 85.8-110.9 in spite of a high boiling point, which means that the NVOC analysis by the HS-SPME method is useful for verification.

\section{ACKNOWLDEGMENTS}

This study was conducted in collaboration with Kyushu University Forests in Japan. The authors thank
Professor Kyoichi Otsuki, Kyushu University Forests for valuable discussion and a lot of great help for field researches. This study was performed with the support of Forest Science \& Technology Projects (Project No. S211214L010110) provided by the Korea Forest Service.

\section{REFERENCES}

Aaltonen, H., J. Pumpanen, M. Pihlatie, H. Hakola, H. Hellén, L. Kulmala, T. Vesala and J. Bäck 2011 Boreal pine forest floor biogenic volatile organic compound emissions peak in early summer and autumn. Agric. For. Meteorol., 151: 682-691

Akutsu, T., S. Tanaka, Y. Murakami, K. Nakajima, Y. Nagashima, Y. Yada, T. Suzuki and K. Sasaki 2006 Effect of the natural fragrance "cedrol" on dopamine metabolism in the lateral hypothalamic area of restrained rats: A microdialysis study International Congress Series, 1287: 195-200

Bräred-Christensson, J. B., K. E. Andersen, M. Bruze, J. D. Johansen, B. G. Bravo, A. G. Arnau, C. L. Goh, R. Nixon and I. R. White 2012 Air-oxidized linalool: A frequent cause of fragrance contact allergy. Contact. Dermatitis., 67: 247-259

Cheng, W. W., C. T. Lin, F. H. Chu, S. T. Chang and S. Y. Wang 2009 Neuropharmacological activities of phytoncide released from Cryptomeria japonica. J. Wood. Sci., 55: 27-31

Dayawansa, S., K. Umeno, H. Takakura, E. Hori, E. Tabuchia, Y. Nagashimac, H. Oosuc, Y. Yadac, T. Suzukic, Y. Onoa and H. Nishijo 2003 Autonomic responses during inhalation of natural fragrance of "Cedrol" in humans. Auton. Neurosci., 108 $79-86$

Dimitriades B. 1981 The role of natural organics in photochemical air pollution. J. Air. Pollut., 31: 229-235

Elson, C. E., T. H. Maltzman, J. L. Boston, M. A. Tanner and M. N. Gould 1988 Anti-carcinogenic activity of d-limonene during the initiation and promotion/progression stages of DMBAinduced rat mammary carcinogenesis. Carcinogenesis, $\mathbf{9}(2)$ 331-332

Guenther, A. B., R. K. Monson and R. Fall 1991 Isoprene and monoterpene emission rate variability: Observations with euca- 
lyptus and emission rate algorithm development. J. Geophys. Res., 96(D6): 10799-10808

Hakola, H., V. Tarvainen, T. Laurila, V. Hiltunen, H. Hellén and P. Keronen 2003 Seasonal variation of VOC concentrations above a boreal coniferous forest. Atmos. environ., 37: 16231634

Ji, D. Y., S. Y. Kim and J. S. Han. 2002 A study on the comparison source profile of the major terpenes from pine tree and korean pine tree. J. KOSAE., 18(6): 515-525

Keith, L. H. and M. M. Walker 1995 Handbook of air toxics: sampling, analysis, and properties. CRC. Press, Lewis Publishers (USA), pp. 182-185

Kesselmeier, J. and M. Staudt 1999 Biogenic Volatile Organic Compounds (VOC): An Overview on Emission, Physiology and Ecology. J. Atmos. chem., 33: 23-88

Kim, S. Y., J. S. Han and H. K. Kim 2001 A study on the source profile of volatile organic compounds from major emission sources. J. KOSAE., 17(3): 233-240

Kim, Y. S., S. J. Park, E. J. Lee, S. M. Lee, C. H. Ryu, G. S. Kim, J. O. Kim and Y. L. Ha 2008 Antibacterial Compounds from Rose Bengal-Sensitized Photooxidation of $\beta$-Caryophyllene. $J$. Food. Sci., 73: C541-C545

Kordali, S., A. Cakir, H. Ozer, R. Cakmakci, M. Kesdek and E. Mete 2008 Antifungal, phytotoxic and insecticidal properties of essential oil isolated from Turkish Origanum acutidens and its three components, carvacrol, thymol and p-cymene. Bioresour. Technol., 99: 8788-8795

Lee, J., B. J. Park, Y. Tsunetsugu, T. Ohira, Kagawa T and Y. Miyazaki 2011 Effect of forest bathing on physiological and psychological responses in young Japanese male subjects. Public. Health., 125: 93-100

Li, Q., A. Nakadai, H. Matsushima, Y. Miyazaki, A. M. Krensky, T. Kawada and K. Morimoto 2006 Phytoncides (wood essential oils) induce human natural killer cell activity. Immunopharm. Immunot., 28: 319-333

Matsunaga, S. N., S. Niwa, T. Mochizuki, A. Tani, D. Kusumoto, Y. Utsumi, T. Enoki and T. Hiura 2013 Seasonal variation in basal emission rates and composition of mono- and sesquiterpenes emitted from dominant conifers in Japan. Atmos. environ., 69: $124-130$

Ohira T. and N. Matsui 2012 Forest medicine. Nova Science Publishers (USA), pp. 25-34
Osman, C., O. Ilknur, T. Sadettin, S. Yildiz and H. Oguzturk 2011 Antioxidative effects of curcumin, b-myrcene and 1,8-cineole against 2,3,7,8-tetrachlorodibenzo-p-dioxin induced oxidative stress in rats liver. Toxicol. Ind. Health., 27(5): 447-453

Pankow, J. F., W. Luo, A. N. Melnychenko, K. C. Barsanti, L. M. Isabelle, C. Chen, A. B. Guenther and T. N. Rosenstiel 2011 Volatilizable Biogenic Organic Compounds (VBOCs) with two dimensional Gas Chromatography-Time of Flight Mass Spectrometry (GCXGC-TOFMS): sampling methods, VBOC complexity, and chromatographic retention data. Atmos. Meas. tech., 5: 345-361

Pio, C., C. Alves and A. Duarte 2001 Organic components of aerosols in a forested area of central Greece. Atmos. Environ. 35: $389-401$

Tani, A. and J. Kawawata 2008 Isoprene emission from the major native Quercus spp. in Japan. Atmos. Environ., 42: 45404550

Tani, A., S. Nozoe, M. Aoki and C. N. Hewitt 2002 Monoterpene fluxes measured above a Japanese red pine forest at Oshiba plateau, Japan. Atmos. Environ., 36: 3391-3402

Trapp, D., K. M. Cooke, H. Fischer, B. Bonsang, R. U. Zitzelsberger, R. Seuwen, C. Schiller, T. Zenker, U. Parchatka, T. V. Nunes, C. A. Pio, A. C. Lewis, P. W. Seakins and M. J. Pilling 2001 Isoprene and its degradation products methyl vinyl ketone, methacrolein, and formaldehyde in a eucalyptus. Chemosphere, 3: 295-307

Wang, S. Y., W. C. Lai, F. H. Chu, C. T. Lin, S. Y. Shen and S. T. Chang 2006 Essential oil from the leaves of cryptomeria japonica acts as a silverfish (Lepisma saccharina) repellent and insecticide. J. Wood. Sci., 52: 522-526

Wang, W., N. Li, M. Luo, Y. Zu and Thomas E. 2012 Antibacterial activity and anticancer activity of Rosmarinus officinalis L. essential oil compared to that of its main components. Molecules, 17: 2704-2713

Yang, Z., N. Wu, Y. Zu and Y. Fu 2011 Comparative Anti-Infectious Bronchitis Virus (IBV) Activity of (-)-Pinene: Effect on Nucleocapsid (N) Protein. Molecules, 16: 1044-1054

Yatagai, M., M. Ohira, T. Ohira and S. Nagai 1995 Seasonal variations of terpene emission from trees and influence of temperature, light, and contact stimulation on terpene emission. Chemosphere, 30(6): 1137-1149 